\title{
A CADEIA PRODUTIVA DO AÇAÍ: ESTUDO DE CASO SOBRE TIPOS DE MANEJO E CUSTOS DE PRODUÇÃO EM PROJETOS DE ASSENTAMENTOS AGROEXTRATIVISTAS EM ABAETETUBA, PARÁ THE AÇAÍ PRODUCTION CHAIN: CASE STUDY ON MANAGEMENT TYPES AND PRODUCTION COSTS IN AGROEXTRACTIVE SETTLEMENT PROJECTS IN ABAETETUBA, PARÁ
}

\section{Márcia de Pádua Bastos Tagore ${ }^{1}$ Marcílio de Abreu Monteiro ${ }^{2}$ Otávio Do Canto ${ }^{3}$}

\section{RESUMO}

O açaizeiro é uma palmeira nativa da Amazônia, de onde é extraída a polpa com alto valor nutritivo, denominada no estado do Pará (região norte do Brasil) de Açaí. O açaí é um dos produtos de maior importância na economia e na dieta alimentar dos paraenses, em especial das famílias que vivem às margens das várzeas, sendo a principal fonte de renda da maioria dos ribeirinhos da região paraense. A crescente demanda pelo produto, por novos mercados em nível nacional e mundial, implicou em aumento de áreas de plantio e alterações no manejo de açaizais tradicionalmente extrativistas, ocasionando mudanças no contexto social, econômico e ambiental. O presente trabalho da pesquisa apresenta resultados do estudo de caso nas várzeas do município de Abaetetuba, considerado um dos maiores produtores do Estado do Pará. A pesquisa de campo evidenciou as relações da cadeia produtiva do açaí no município e demonstrou diferentes tipos de manejo de produção atualmente utilizados em projetos de assentamento agroextrativista, bem como levantou os custos e renda de produção de unidades selecionadas. A pesquisa apontou que as ações e o manejo do açaí em áreas de várzea precisam deixar de focar no crescimento de produção para buscar investir em intervenções de manejo de baixo impacto evitando as problemáticas advindas do adensamento da espécie e a homogeneização da paisagem, com foco na conservação do ecossistema, pois o contrário não se justifica, sequer pela análise econômica. O sistema creditício deve focar também, na promoção da verticalização da cadeia produtiva.

Palavras Chave: Cadeia produtiva. Açaí. Manejo. Amazônia. Várzea.

Manuscript first received/Recebido em 16/12/2019 Manuscript accepted/Aprovado em: 23/12/2019

1 Doutoranda em Gestão dos Recursos Naturais e Desenvolvimento Local na Amazônia pelo Núcleo de Meio Ambiente (NUMA) da Universidade Federal do Pará - UFPA. Mestre em Gestão dos Recursos Naturais e Desenvolvimento Local na Amazônia pelo NUMA da UFPA. Responsável pela Cadeia Produtiva do Dendê pela Secretaria de Estado de Desenvolvimento da Agricultura e da Pesca (SEDAP) no Pará. E-mail: mpbtagore2019@gmail.com

2 Doutor em Ciências do Desenvolvimento Socioambiental pelo Núcleo de Altos Estudos Amazônicos (NAEA) da Universidade Federal do Pará - UFPA. Pesquisador no Grupo de Pesquisa Dinâmica Agrária e Desenvolvimento Sustentável na Amazônia (Dadesa) no NAEA/UFPA. E-mail: marcilio.amonteiro@gmail.com

${ }^{3}$ Doutor em Desenvolvimento Rural pela Universidade Federal do Rio Grande do Sul - UFRGS. Docente do Programa de Pós-Graduação em Gestão de Recursos Naturais e Desenvolvimento Local na Amazônia (PPGEDAM) do Núcleo de Meio Ambiente (NUMA) da Universidade Federal do Pará - UFPA. E-mail: odocanto@ gmail.com 


\begin{abstract}
The açaizeiro is a palm tree native to the Amazon, from which the pulp with high nutritional value is extracted, called in the state of Pará (northern region of Brazil) of Acai Berry. Acai berry is one of the most important products in the economy and food diet of pará, especially families living on the banks of the floodplains, being the main source of income of most riversides in the region of Pará. The growing demand for the product, for new markets at the national and global level, involved increasing planting areas and changes in the management of traditionally extractivist açaizais, causing changes in the social, economic and environmental context. The present study of the research presents results of the case study in the floodplains of the municipality of Abaetetuba, considered one of the largest producers in the State of Pará. The field research showed the relationships of the production chain of acai berry in the municipality and demonstrated different types of production management currently used in agroextractivist settlement projects, as well as raised the costs and income of production of units Selected. The research pointed out that the actions and management of acai berry in lowland areas need to stop focusing on production growth to seek to invest in low-impact management interventions avoiding the problems arising from the density of the species and the homogenization of the species landscape, focusing on the conservation of the ecosystem, because the opposite is not justified, even by economic analysis. The credit system should also focus on promoting the verticalization of the production chain.
\end{abstract}

Keywords: Production chain. Acaí. Management. Amazon. Mangrove.

\title{
1 INTRODUÇÃO
}

O açaizeiro (Euterpe oleracea Mart.) é uma palmeira natural das várzeas da Amazônia e é base alimentar de grande parte da população ribeirinha ${ }^{4}$ paraense, que também tem no açaí, sua principal fonte econômica respondendo por grande parte de sua renda (JARDIM, 1996; LOPES; SANTANA, 2005; ANDRADE et al., 2008; NOGUEIRA; HOMMA, 2014).

O Pará é o maior produtor nacional da polpa de açaí, equivalente a 1.274 .056 t de fruto produzido (IBGE, 2018). São 252,5 mil hectares de produção, com a maior área plantada com sistema de irrigação,1.500 hectares na cidade de Óbidos de propriedade do Sr. Luiz Vaccaro, da Indústria "Açaí Amazonas". O Estado do Pará é também o maior consumidor do fruto (CONAB, 2015). Em 2016, foi o produto da extração vegetal não madeireira com maior valor da produção estadual (IBGE, 2016). Atualmente, o açaí é referência alimentar e nutricional no mundo, influenciando o setor turístico do Estado.

Não existem dados precisos de quantidade de pontos de venda de açaí no Estado, mas a associação de batedores de açaí estima 8 mil pontos de venda de açaí na Região Metropolitana de Belém. A atividade gera muitos empregos diretos em toda sua cadeia de produtiva, da coleta e manejo, até a comercialização e beneficiamento do fruto, onde estão envolvidos muitos atores sociais, que segundo Oliveira (2016) envolve mais de 300 mil pessoas, em 54 municípios, representando cerca de $70 \%$ da renda da população ribeirinha.

\footnotetext{
${ }^{4} \mathrm{O}$ termo ribeirinho designa as pessoas que vivem nas várzeas às margens dos rios e segundo Diegues (1999) as práticas de extrativismo, atividades aquáticas e florestais são características dessa população.
} 
O interesse pela elevação da produção do fruto tem se dado principalmente pela visibilidade do produto associado ao valor nutritivo e energético do alimento (SANTANA et al.; COSTA et al., 2006) e que nos últimos anos vem ganhando grande expressão econômica.

Segundo Fontes \& Ribeiro (2012) o processo de produção do açaí ganha nova conformidade a fim de atender a demanda das indústrias resultando em certa padronização das plantações, surgindo dessa forma, os novos açaizais.

A base produtiva extrativa do açaí foi sobreposta pela base produtiva de cultivo ou manejo (LOPES; SANATANA; CARVALHO 2005) com o desafio de fornecer às indústrias polpa em grande quantidade e regularidade, visto que existem dois períodos distintos de produção, a safra e a entressafra (OLIVEIRA et al., 2007; HOMMA, 2006; NEVES, 2014).

Apesar de produzir o ano todo, o período da safra no Pará, ocorre na época da estiagem das chuvas, de julho a dezembro, quando apresenta as maiores produções, e nos meses de setembro e outubro. A entressafra ocorre de janeiro à junho.

No território dos Projetos de Assentamento Agroextrativista (PAE) de Aabetetuba, foi possível observar a sobreposição da base produtiva extrativista pela base produtivo de manejo, visto que este território recebeu investimentos públicos nos últimos 13 anos, via dois principais programas do governo federal para a agricultura familiar: na área de assentamentos rurais, através do PAE; e na área de financiamento creditício para a produção agrícola, em especial o açaí, através do Pronaf. A modalidade de projeto de assentamento PAE, criada em 1996, com foco na Região Amazônica, tinha como objetivo regularizar as terras para populações extrativistas que já se encontravam nas áreas da União.

O estudo de caso foi realizado em Abaetetuba, Pará, baseado na análise de informações de 56 famílias dispersas em 24 Projetos de Assentamento Agroextrativista (PAE) das 72 ilhas que compõem o município, com objetivo de analisar a cadeia produtiva do açaí, os investimentos públicos para produçãode açaí, os tipos de manejo adotados e os custos de produção em áreas de várzea de PAEs.

O presente artigo inicia apresentando um breve histórico do açaí no Estado do Pará, com ênfase nas características de produção, forma de coleta do fruto, beneficiamento e consumo destacando as pricipais características das décadas como o período do "Boom do açaî" e os novos mercados. Em seguida, apresenta-se a descrição metodológica e a opção do método qualitativo de estudo de caso em PAEs de Abaetetuba, Pará.

Com a finalidade de subsidiar a análise, é descrito o fluxograma da complexa cadeia produtiva do açaí em Abaetetuba e a abordagem de ações de políticas públicas, como o PRONAF, com financiamento de investimento e custeio com crédito produtivo e fomento à produção, Assistência Técnica e Extensão Rural - ATER e Assentamentos Rurais.

Por fim, categoriza-se as formas de manejo e apresenta-se os custos de produção do açaí. A partir da análise dos dados, faz-se recomendações para subsidiar políticas públicas.

\section{NOVOS MERCADOS PARA O AÇAÍ}

No Brasil são encontradas cinco espécies do gênero Euterpe: Euterpe oleracea Martius (açaizeiro), E. precatoria Martius (açaí solitário), E. edulis Martius (jussara), E. catinga Wallace (açaízinho) e E. longebracteata Barbosa Rodrigues (açaí de mata) produzem frutos arredondados de cor violáceo-púrpura (SCHIRMANN, 2009). Sendo a espécie Euterpe oleracea Martius (açaizeiro) de touceira (estipes) a predominante no Pará. 
É rico em antocianina, que combate radicais livres e previne o envelhecimento precoce; tem alto teor de fibras, o que lhe confere o valor energético; possui também, minerais e vitaminas, ácidos graxos e proteínas superior ao leite e ovo (OLIVEIRA et al., 2007). Segundo Rogez (2000) o açaí é capaz de suprir cerca de $65 \%$ das necessidades de lipídeos e de $25 \%$ a $65 \%$ de proteínas necessária ao ser humano.

Com aumento do processo de urbanização nas décadas de 1960 e 1970, o açaizeiro apresentou um acréscimo de consumo registrado nos centros urbanos, saindo das áreas rurais, para ocupar as periferias das cidades. Por outro lado, nesse período é registrada a ocorrência de derrubada de grandes áreas de açaizais nativos para extração de palmito (HOMMA, 2014) frente a diminuição do estoque da palmeira juçara (Euterpe edulis Mart) na Mata Atlântica (ANDERSON, 1992; NOGUEIRA; HOMMA, 2014).

Na década de 1980, a diminuição das palmeiras do sudeste do país decorrentes da extração predatória para retirada do palmito, fez com que o açaí do Pará ganhasse relevância em termos comerciais.

Na década de 1990, segundo Nogueira \& Homma (2014), o palmito se destacou como produto de exportação do Pará, diminuindo, contudo, o estoque de plantas para produção de polpa. Contudo, o suco de açaí começa a fazer sucesso como energético natural nas academias de ginásticas com crescimento do comércio da polpa congelada para os estados do Rio de Janeiro, São Paulo, Minas Gerais, Rio Grande do Sul e Goiás (MOURÃO, 1996; ROGEZ, 2000). Essa procura nesse setor do mercado atinge as classes de maior poder aquisitivo (SANTANA et al, 2006).

Nas décadas de 2000 e 2010, essa tendência se confirma, consolidando o açaí como importante produto de mercado. Em 2014, os países importadores de polpa de açaí foram os Estados Unidos $(48,77 \%)$ e o Japão $(41,66 \%)$ sendo o restante $(9,57 \%)$ importados por 29 países da Europa, com um volume de $4.983 .812 \mathrm{~kg}$, correspondendo à US\$22,523 milhões, que segundo Tavares \& Homma (2015). Para efeito didático, o processo histórico do açaí foi agrupado três fases (Quadro 1).

Quadro 1 - Resumo do histórico do açaí no Pará

\begin{tabular}{|c|c|c|c|c|c|c|}
\hline $\begin{array}{l}\text { Fases } \\
\text { Até } \\
\text { década } \\
1970\end{array}$ & Produção & $\begin{array}{l}\text { Coleta do Fruto } \\
\text { Uso da } \\
\text { peconha* }\end{array}$ & $\begin{array}{l}\text { Beneficiamento } \\
\text { Local de } \\
\text { produção }\end{array}$ & $\begin{array}{l}\text { Extração } \\
\text { Manual com } \\
\text { peneira }\end{array}$ & $\begin{array}{l}\text { Consumo } \\
\text { Segurança } \\
\text { alimentar }\end{array}$ & $\begin{array}{l}\text { Características } \\
\text { Valor cultural e } \\
\text { alimentar (suco para } \\
\text { consumo familiar) }\end{array}$ \\
\hline $\begin{array}{l}1970 \text { a } \\
1990\end{array}$ & Extrativista & Uso da peçonha & $\begin{array}{l}\text { Local de } \\
\text { produção e } \\
\text { periferias dos } \\
\text { centros urbanos }\end{array}$ & $\begin{array}{l}\text { Manual com } \\
\text { peneira e } \\
\text { máquina } \\
\text { batedora } \\
\text { artesanal }\end{array}$ & $\begin{array}{l}\text { Segurança } \\
\text { alimentar } \\
\text { e comércio } \\
\text { local }\end{array}$ & $\begin{array}{l}\text { Demanda por } \\
\text { palmito e diminuição } \\
\text { da oferta de açaí }\end{array}$ \\
\hline $\begin{array}{l}1990 \\
2000 \\
2010\end{array}$ & $\begin{array}{l}\text { Extrativista, } \\
\text { plantio em } \\
\text { várzea, } \\
\text { plantio em } \\
\text { terra firme. }\end{array}$ & $\begin{array}{l}\text { Uso da peconha, } \\
\text { equipamento de } \\
\text { coleta }\end{array}$ & $\begin{array}{l}\text { Periferias dos } \\
\text { centros urbanos, } \\
\text { bairros centrais } \\
\text { e distritos } \\
\text { industriais. }\end{array}$ & $\begin{array}{l}\text { Máquina } \\
\text { batedora } \\
\text { artesanal, } \\
\text { máquina } \\
\text { industrial } \\
\text { e câmara } \\
\text { frigorífica. }\end{array}$ & $\begin{array}{l}\text { Segurança } \\
\text { alimentar, } \\
\text { comércio } \\
\text { local, } \\
\text { nacional e } \\
\text { internacional. }\end{array}$ & $\begin{array}{l}\text { "Boom" da demanda } \\
\text { pelo açaí, resgate } \\
\text { cultural, manejo } \\
\text { da várzea, novas } \\
\text { variedades e } \\
\text { tecnologias com uso } \\
\text { de irrigação em terra } \\
\text { firme. }\end{array}$ \\
\hline
\end{tabular}

*Apetrecho de fibra utilizado para apoiar os pés de encontro ao caule do açaizeiro de forma a facilitar a escalada na árvore. Fonte: Adaptado pelos autores a partir de NOGUEIRA e HOMMA (2014) e MOURÃO (2010).

Esses novos mercados resultaram na expansão de açaizais manejados em áreas de várzeas (NOGUEIRA et al 2005; HOMMA, 2014) e em terra firme, concentrando-se principalmente no Nordeste Paraense. 
Em 2003, observou-se uma ligeira queda de produção que pode ser atribuído ao baixo valor de mercado do produto. Com o crescimento do valor de produção, gerou a estabilização da produção até o ano de 2007, com retomada de crescimento em 2008, impulsionada pela elevação do valor da produção mantendo-se crescente, até o presente momento.

O grande diferencial de crescimento de produção e valor se dá em 2011. O crescimento da demanda tem como fator propulsor o crescimento do valor de mercado que desde 2007 apresenta curva ascendente e que acaba por resultar no aumento da produção, decorrendo do processo de intensificação do manejo dos açaizais apoiados por políticas públicas.

Nos últimos 15 anos têm ocorrido um descolamento entre a oferta e a demanda, onde a produção não tem sido suficiente para atender o mercado, o que tem levado ao aumento de preço do produto.

Em relação à oferta do produto destaca-se o papel das instituições, em especial as de fomento e ATER, como o agente financeiro Banco da Amazônia, S. A. (BASA) e a Assistência Técnica e Extensão Rural do Estado do Pará (EMATER-PARÁ), atuando sobre a cadeia do açaí a partir de custeio e investimento através do PRONAF, influenciado diretamente nas dinâmicas para aumento de produção e produtividade.

As Políticas Públicas implementadas na região, vêm sendo marcadas pelos interesses e estratégias de expansão das relações capitalistas resultando em programas e ações impulsionadas pela demanda do produto (CHAVES, 2001).

\section{METODOLOGIA DA PESQUISA}

A opção do método de estudo de caso se deu por permitir uma ação exploratória e descritiva a partir de planejamento, com aplicação de teoria aplicados em casos únicos ou multiplos (YIN, 1999), com coleta e análise de dados.

A pesquisa foi realizada no município de Abaetetuba, distante $68 \mathrm{~km}$ de Belém, Capital do Estado. Integra uma das áreas de maior produção de açaí do estuário amazônico. Possui 72 Ilhas, com 24 Projetos de Assentamentos Agroextrativistas (PAE) criados pelo Instituto Nacional de Colonização e Reforma Agrária (INCRA) (Mapa 1).

Mapa 1 - 24 PAEs do município de Abaetetuba, Pará e ribeirinhos pesquisados.

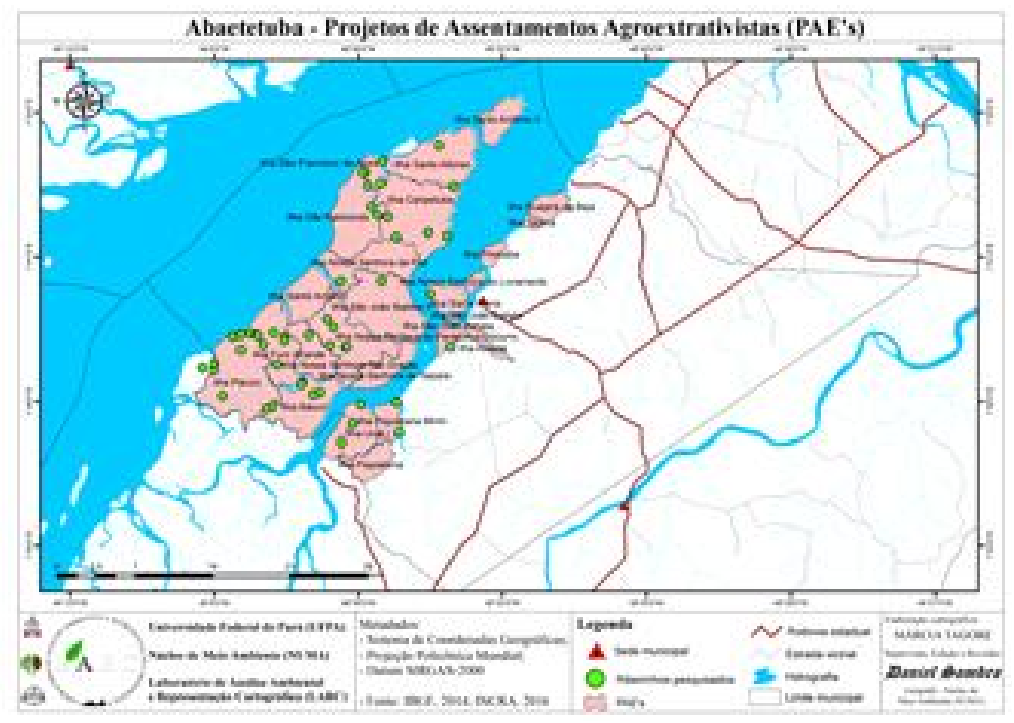

Fonte: Adaptado pelos autores a partir de IBGE (2014) e INCRA (2016). 
Os dados do projeto de açaí, como valor financiado, tipo de manejo, localização da propriedade, fluxograma da cadeia produtiva e custos de produção, foram coletados a partir do levantamento de registro de informações de ribeirinhos que obtiveram financiamento via Programa de Financiamento da Agricultura Familiar (PRONAF) no período entre os anos de 2003 a 2015, com base nas Declarações de Aptidão (DAP). A partir deste levantamento, foi realizada seleção de forma aleatória de 56 ribeirinhos e análise de campo em 10 propriedades, desenvolvida junto à equipe da Empresa de Assistência Técnica e Extensão Rural do Estado do Pará - EMATER - PARÁ, por ocasião das visitas de ATER na propriedade do ribeirinho.

Foram realizadas entrevistas semiestruturados e aplicados questionários durante as visitas às 10 propriedades dos ribeirinhos, além dos representantes institucionais da prefeitura, EMATER, Associação, Cooperativa e do Sindicato de Trabalhadores Rurais do município.

\section{A COMPLEXA CADEIA PRODUTIVA DO AÇAÍ}

A concentração das indústrias de processamento de polpa de açaí se encontra na Região Nordeste do Estado, principalmente no município de Castanhal devido sua posição estratégica para escoamento do produto. A destinação da produção do açaí compreende diferentes mercados. Apesar de grande parte atender a demanda nacional e internacional, ainda é bastante representativa a destinação para o mercado local e autoconsumo familiar (BEZERRA et al 2016).

Em todas as etapas do processo de produção, seja extrativismo ou plantio; comercialização; e beneficiamento, existe um arranjo envolvendo relações estabelecidas entre os agentes que fazem parte da cadeia produtiva.

Segundo kliemann \& Souza (2003) a cadeia produtiva é entendida como um sistema complexo, envolvendo o setor econômico de um determinado produto, onde a agricultura é considerada como um sistema amplo onde participam os produtores, agroindústrias e os segmentos de distribuição e comercialização com sucessão de etapas.

A cadeia produtiva está relacionada com campesinato e biodiversidade, onde ocorre influencia do mercado, com inserção de técnicas/tecnologias em processos sociais, econômicos e políticos que influenciam na dinamica ambiental (COSTA; NUNEZ, 2017)

Entender a cadeia produtiva do açaí, portanto, é importante para qualquer trabalho que se proponha a abordar seu papel econômico, social e ambiental, considerando-se que existe uma economia invisível superior a que vem sendo apresentada pelas estatísticas oficiais do Instituto Brasileiro de Geografia e Estatística (IBGE), incluindo a produção consumida no núcleo familiar

A partir dos levantamentos realizados em campo, junto aos ribeirinhos dos PAEs de Abaetetuba, Pará, foi construído o Fluxograma apresentado na Figura 1 que apresenta os elos da cadeia produtiva, a partir da produção, comercialização e beneficiamento. 
Figura 1 - Fluxograma da Cadeia produtiva do açaí no município de Abaetetuba, Pará.

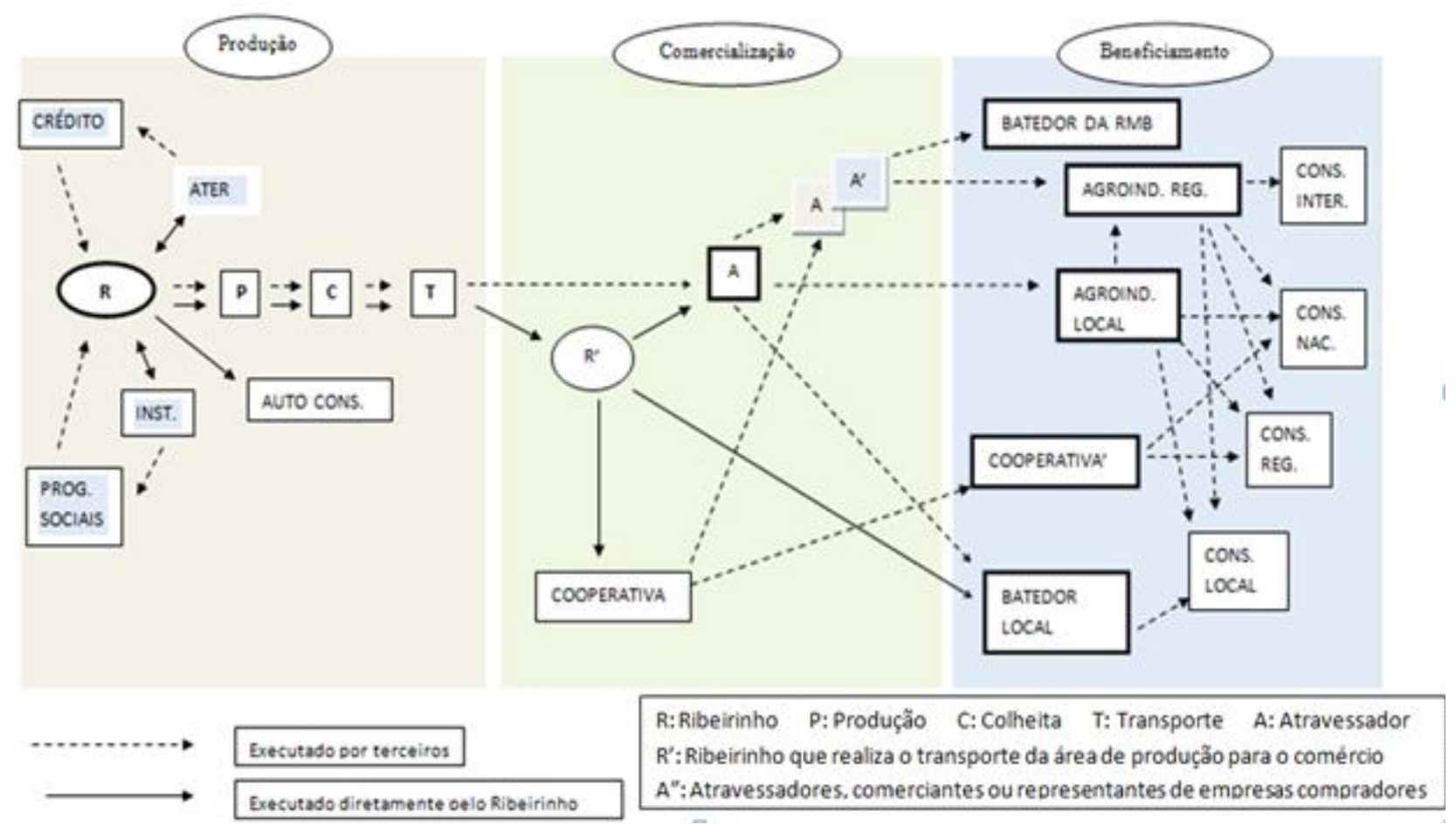

Fonte: Elaborado pelos autores (2016)..

No elo de produção da cadeia, observa-se que os ribeirinhos $(\mathrm{R})$ vivem da produção e extrativismo do açaí, pesca de peixe e camarão. Eles se identificaram também como ribeirinho/pescador (60\%) e ribeirinho/lavrador $(40 \%)$.

Os recursos financeiros provenientes do PRONAF (CRÉDITO) foram disponibilizados pelos, como Banco do Brasil e Banco da Amazônia S.A., via PRONAF/FNO, e as instituições públicas (INST.) envolvidas diretamente, foram: a Prefeitura municipal; a EMATER; os agentes financeiros; e o INCRA.

Todas as famílias (100\% dos entrevistados) receberam algum benefício via programas sociais (PROG. SOCIAIS), como: PAE, o bolsa família, e seguro defeso. Todos os entrevistados receberam financiamento para o manejo do açaí, via as empresas de ATER. O recurso foi empregado, principalmente, na contratação de mão de obra complementar à familiar. As atividades compreendem, em geral, a limpeza de área com roçagem, raleamento da vegetação, com retirada de plantas indesejáveis, retirada de cipós, desbaste das touceiras com eliminação dos estipes mais altas e a retirada de palmito.

A produção $(\mathrm{P})$ compreende os transplantios de mudas de crescimento espontâneo na área e o plantio, derrubada, roçagem, desbaste, transplantio, produção de mudas e plantio direto que são realizadas pelos membros da família, em sistema de mutirão, e/ou com trabalhadores contratados.

A colheita (C) é realizada de forma tradicional com o auxílio da peconha para a retirada dos cachos que são debulhados no próprio local de coleta. Embora haja a recomendação técnica para que a área seja forrada por ocasião da debulha, apenas $50 \%$ declararam que utilizam o encerado. $\mathrm{O}$ fruto é depositado nos cestos de palha ou basquetas plásticas. É realizada de forma familiar, mutirão ou contrato de trabalhador.

Parte do fruto colhido fica na propriedade para o consumo familiar (AUTO CONS.) uma vez que consomem em média 2 litros/família/dia, ou seja, parte da colheita é destinada ao consumo diário 
da família. O transporte ( $\mathrm{T}$ ) do fruto é realizado tanto pelo ribeirinho ( $\left.\mathrm{R}^{\prime}\right)$, quanto pelos atravessadores comerciantes (A), que compram o açaí in natura dos ribeirinhos, ou por e atravessadores representantes de empresas(A"), que compram o fruto in natura em grandes quantidades do varejo rural (e/ou do produtor) e vendem para agroindústrias estaduais.

A comercialização se dá: na residência do ribeirinho; no porto; ou em pontos da sede do município. O pagamento é em espécie, e os frutos são transportados em embarcações como canoas, rabetas ou rabudas (com capacidade média variando entre 10 e 180 rasas) e barcos.

O açaí é destinado em nível local para venda aos: comerciantes que possuem máquinas despolpadeiras, chamadas de "batedores de açaî" (BATEDOR LOCAL), que vendem a polpa do açaí para os consumidores locais; e à empresa (AGROIND. LOCAL) que realiza o processamento do açaí in natura, como a Indústria e Com. Nobre Ltda, detentora da marca Imperador de palmito em conserva, que está em funcionamento no município, desde 2008.

A cooperativa de fruticultores de Abaetetuba - COFRUTA (COOPERATIVA) fundada em 2002 possui 88 cooperados, e compra a produção de açaí, tanto dos associados quanto de ribeirinhos não cooperados, e fornece para empresas.

Abaetetuba tem uma localização estratégica, atrativa para se tornar polo de beneficiamento do produto. Atualmente, o porto de Igarapé Miri registre parte de sua produção.

A produção também chega às unidades artesanais de beneficiamento em Belém (BATEDOR DA RMB), que produzem e vendem o suco para a população local.

$\mathrm{O}$ açaí chega às ndústrias estaduais (AGROIND. REGIONAL) através de atravessadores, comerciantes ou representantes de empresas compradoras ou atavés da agroindústria local (AGROIND. LOCAL). A agroindústria regional beneficiam o açaí em polpa pasteurizada e/ou congelada e unidades de transformação da produção estadual. Em geral, são processadoras e beneficiadoras de polpa, geleias, compotas, blends (misturado com outras frutas) e sorvetes e voltam para o consumo local, consumidor reginal, consumidor nacional e/ou consumidor internacional.

Foi identificado o consumidor final no município, denominado de consumidor local (CONS. LOCAL); o consumidor final no Estado, denominado de consumidor regional (CONS. REG.); o consumidor final de outros estados, enquanto consumidores nacionais (CONS. NAC.); e consumidor final internacional (CONS. INTER.).

A cadeia produtiva do açaizeiro embora tenha um start produtivo efetivo em nível local, sua dimensão ultrapassa fronteiras geográficas e interesses diversos, o que dificulta o acompanhamento e sua mensuração. Por ser uma cultura sazonal tem influencias de valores a partir de demanda e oferta, mas por ter um peso muito forte de cunho cultural acaba respondendo à economia de forma diferenciada.

A cadeia do açaí vem sendo impulsionada por agentes e programas de Estado, como o BASA através do PRONAF, a Secretaria de Estado de Desenvolvimento Agropecuário e da Pesca (SEDAP), EMATER-PARÁ, Agência de Defesa Agropecuária e da Pesca (ADEPARA), entre outros. Estas instituições, através de seus programas, se por um lado desempenham o papel de propulsor do desenvolvimento do Estado, que em princípio se apresentam como solução para a melhoria de renda e inserção social dos ribeirinhos. Por outro lado, também exercem forte influência na pressão sobre os ecossistemas, sendo desta forma, corresponsáveis nas alterações advindas desse processo. 
Estas ações de fomento, seja através de crédito, ou sementes e implementos, seja de ATER estão focando no aumento da produção e produtividade, sem o devido acompanhamento dos impactos advindos de determinadas atividades, como por exemplo, o adensamento da cultura do açaí nas áreas de várzea, cujo ecossistema é sensível e de difícil regeneração. (HOMMA, 2014).

Ressalta-se que um programas propulsores do aumento de produção de açaí é o Programa de Fortalecimento da Agricultura Familiar (PRONAF). Entre os anos de 2003 a 2015 Abaetetuba recebeu expressivo recursos advindos de projetos financiados via PRONAF, através do agente financeiro Banco da Amazônia, S. A. (BASA).

Segundo a Empresa de Assistência Técnica e Extensão Rural do Estado do Pará (EMATERPARÁ) sua equipe do escritório local de Abaetetuba elabora anualmente um número significativo de projetos, ainda que atuem no município outras empresas que prestam serviços de ATER e que também exercem essa atividade. Só em 2015 foram aprovados 248 projetos de açaí, elaborados pela equipe local da EMATER-PARÁ, totalizando um valor financiado de R\$3.419.529,00.

Das 24 ilhas que são Projetos de Assentamentos Agroextrativistas (PAE), 9 tiveram projetos de açaí financiados no ano de 2015 e receberam outros financiamentos via PRONAF A, onde a maioria (39\%) apresenta área de açaí financiada entre 5 a 10 hectares.

Os PAEs pressupõem o sistema extrativista baseado na coleta e extração de modo sustentável, com objetivo de assegurar o uso sustentável dos recursos naturais da unidade. A criação do PAE é de responsabilidades do Instituto Nacional de Colonização e Reforma Agrária (INCRA), e neles é permitido atividades extrativistas e de manejo, sendo que a atividade de manejo do açaí nas várzeas é disciplinado pela Secretária do Patrimônio da União (SPU) através de autorização de uso para o desbaste de açaizais, colheita de frutos ou manejo de outras espécies extrativistas, conforme o artigo $1^{\circ}$ da portaria (SPU, 2005).

\section{A PRODUÇÃO DE AÇAÍ NOS PROJETOS DE ASSENTAMENTOS AGROEXTRATIVISTAS DE ABAETETUBA}

A pesquisa demonstrou que $100 \%$ dos entrevistados vêm aumentando suas áreas de produção com o incremento de açaí, onde fica evidenciada a atividade de manejo envolvendo eliminação de espécies naturais do ecossistema de várzea para obter maior produção com alteração no sistema tradicional resultando em homogeneização da paisagem, a partir de transplantio e plantio de mudas de açaí, resultando em áreas de monocultivo dessa espécie.

$\mathrm{Na}$ atividade produtiva do açaí realizada pelos ribeirinhos foram identificados diferentes tipos de manejo, agrupados por características comuns das atividades que envolve principalmente a eliminação de espécies, o adensamento da área com açaí a partir de transplantio e plantio e consequentemente a quantidade de plantas por hectare, bem como, a quantidade de estipes/planta em três tipos: extrativismo com manejo de baixo impacto, manejo de médio impacto e manejo intensivo de alto impacto (Quadro 2). 
Quadro 2 - Tipos de manejo adotado pelos ribeirinhos

\begin{tabular}{|l|l|}
\hline $\begin{array}{l}\text { Tipo de manejo } \\
\begin{array}{l}\text { Extrativismo com } \\
\text { manejo de baixo } \\
\text { impacto }\end{array}\end{array}$ & $\begin{array}{l}\text { Caracterização das atividades } \\
\text { Coleta de frutos; eliminação de cipós e plantas mais altas; em torno de5 estipes/planta; até 300 } \\
\text { plantas }\end{array}$ \\
\hline $\begin{array}{l}\text { Manejo de médio } \\
\text { impacto }\end{array}$ & $\begin{array}{l}\text { Retirada de algumas espécies; desbaste do número de estipes de açaizeiro por touceira; aberturas } \\
\text { de trilhas para o escoamento do produto; aproximadamente 5 estipes por planta com até } 400 \\
\text { plantas/há }\end{array}$ \\
\hline $\begin{array}{l}\text { Manejo intensivo } \\
\text { de alto impacto }\end{array}$ & $\begin{array}{l}\text { Eliminação das outras espécies, deixando praticamente só o açaizeiro; aberturas de canais de } \\
\text { escoamento; enriquecimento com mudas ou transplantio de mudas de açaí; aproximadamente } 3 \text { a } \\
\text { 4 estipes por planta com mais de 400 plantas/ha. }\end{array}$ \\
\hline
\end{tabular}

Fonte: Elaborado pela autora com base em visita exploratória de campo (2016).

A categoria de manejo intensivo de alto impacto foi a que concentrou maior número de ribeirinhos com enquadramento de $60 \%$ deles, ou seja, eliminam as espécies consideradas concorrentes por sol, água e nutrientes, ocasionando uma homogeneidade da área a partir do açaí. (Quadro 3).

Quadro 3 - Percentual de ribeirinhos entrevistados por tipo de manejo de açaí utilizado.

\begin{tabular}{|l|c|}
\hline Tipos de Manejo & Percentual \\
\hline Manejo de alto impacto & $60 \%$ \\
\hline Manejo de médio impacto & $30 \%$ \\
\hline Manejo de baixo impacto & $10 \%$ \\
\hline
\end{tabular}

Fonte: Elaborado pelos autores (2016).

Em função da produção sazonal dos açaizeiros, existe uma grande diferença entre o custo de produção do período de safra e entressafra, cujo acompanhamento e levantamento dos custos de produção e ganhos reais se tornam mais difícil pelo fato de o ribeirinho não realizar o controle e anotação dos custos de entrada e saída com a produção de suas atividades produtivas de um modo geral, inclusive do açaí.

A pesquisa de campo demonstrou que a produtividade do açaí adensado de médio impacto, considerando 400 plantas/hectare, foi em média de $9,8 \mathrm{~kg} /$ planta/ano, resultando em torno de 0,7 latas de açaí. Considerando que o custo de produção ao ano fica em torno de R \$2.040,00 com produção de R $\$ 3.920$ $\mathrm{kg}$, o rendimento pode ser considerado bom, chegando $\mathrm{a} \$ 3.718,31$, quando comparado à outras atividades.

Quando comparado com valores de produção do município levantados pela CONAB (2015) de $4.200 \mathrm{~kg} / \mathrm{hectare}$, percebemos uma diferencial de $280 \mathrm{~kg}$ que pode ser atribuído a diferentes fatores uma vez que não há detalhamento da tabela CONAB.

Há de se considerar que durante 6 meses, o açaí não gera lucro em espécie, embora tenha lucro efetivo enquanto alimento da família, ocasião em que o ribeirinho se envolve com outras atividades como pesca de peixes e camarão.

Nesse sentido, para o cálculo das despesas no período da entressafra, foi computado os valores pagos com mão de obra familiar e a contratada, bem como, as despesas com colheita do fruto para o consumo da família, que fica em torno de 2 litros por família, sendo que a produção média foi obtida através de percentual, considerando $10 \%$ do consumo total, uma vez que a tabela apresenta dados para 1 hectare, sendo que a maioria dos ribeirinhos que fizeram parte da pesquisa (39\%) trabalham com o açaí em área que varia de 5 a 10 hectares. 
Tabela 2 - Custo de produção de açaí de várzea com adensamento médio de 400 plantas/hectare em Abaetetuba, Pará, ano 2016.

\begin{tabular}{|c|c|c|c|c|c|c|c|c|c|}
\hline $\begin{array}{c}\text { Produção } \\
\text { no período }\end{array}$ & $\begin{array}{c}\text { Produção } \\
\text { média } \\
\text { (kg) }\end{array}$ & $\begin{array}{c}\text { Preço } \\
\text { médio } \\
\text { do kg } \\
\text { (R\$) }\end{array}$ & $\begin{array}{l}\text { Quantidade } \\
\text { de rasas/ha } \\
\text { (uni.) }\end{array}$ & $\begin{array}{c}\text { Preço } \\
\text { médio da } \\
\text { rasa }(\mathbf{R} \$)\end{array}$ & $\begin{array}{c}\text { Renda } \\
\text { bruta } \\
\text { (R\$) }\end{array}$ & $\begin{array}{c}\text { Despesas } \\
\text { com mão } \\
\text { de obra } \\
\text { - tratos } \\
(\mathbf{R} \$)\end{array}$ & \begin{tabular}{|c} 
Despesas \\
com mão \\
de obra- \\
colheita \\
$(\mathbf{R} \$)$
\end{tabular} & $\begin{array}{c}\text { Despesas } \\
\text { Totais } \\
\text { (R\$) }\end{array}$ & $\begin{array}{c}\text { Renda } \\
\text { líquida } \\
\text { (R\$) }\end{array}$ \\
\hline Safra & 3.528 & 1,19 & 126 & 33,32 & 4.198 & - & 1.260 & 1.260 & 2.938 \\
\hline Entressafra & 392 & 2,79 & 14 & 78,12 & 1.093, & 640,00 & 140 , & 780 & 313, \\
\hline Anual & 3.920 & - & 140 & - & 5.292 & 640 & 1.400 & 2.040 & 3.252 , \\
\hline
\end{tabular}

Obs. Não foram computados os valores com a venda do palmito, quando dos tratos culturais.

Fonte: Elaborado pelos autores (2016).

Considerando que a média dos ribeirinhos (39\%), explora de 5ha a 10 há de açaí, 5 hectares em produção em áreas de várzea com manejo de adensamento médio de 400 plantas, a produção média é de $19.600 \mathrm{~kg}$ gerando uma renda líquida de $\mathrm{R} \$ 16.260,00$ anual sem contabilizar a venda do palmito quando da eliminação das estipes.

Embora a mão de obra utilizada seja preferencialmente a familiar, o que ficou constatado é que com o aumento da área de produção, há efetiva necessidade de contratação de mão de obra externa, com média de 4 contratados, sendo que no período da safra, a atividade de trabalho se concentra na colheita; e na entressafra, as atividades abrangem os tratos culturais, como limpeza, principalmente a eliminação de plantas de outras espécies, poda de estipes mais velhas e altas, transplantio, plantio, abertura de canais de escoamento e outros.

Ressalta-se o valor diferenciado do serviço de mão de obra, quando nas atividades de tratos culturais, é pago em forma de diária ( $\mathrm{R} \$ 40,00)$, e quando da colheita, os apanhadores cobram por rasa $(\mathrm{R} \$ 10,00)$.

Dois fatores de relevância devem ser considerados: 1) a sazonalidade onde a receita é bastante diferenciada, obtida nos períodos de safra e entressafra com diferencial acima de 100\%; 2) o adensamento dos açaís acima de 400 plantas/hectare, que não consegue responder à expectativa de produção, pois tem demonstrado fatores limitantes no aumento de produtividade. $\mathrm{O}$ incremento de maior número de indivíduos numa mesma área tem seus limitantes com, por exemplo, o espaçamento mínimo necessário entre plantas de forma a permitir que se desenvolvam, sem que suas copas se entrelacem, garantindo luminosidade para as mesmas e desenvolvimento sadio dos cachos.

Os dados demonstram está ocorrendo um adensamento da cultura do açaí com homogeneização da paisagem a partir do monocultivo, o que coloca em risco o ecossistema de várzea, ademais, demonstra que embora se busque o aumento de produção e produtividade, isso não vem ocorrendo como demonstrado pelos tipos de manejo adotados e os custos de produção.

A análise aponta que os investimentos públicos para produção de açaí precisam ser acompanhadas de ações voltadas para a preocupação com a sustentabilidade social e ambiental, para além da econômica.

Fica evidenciado que a cadeia produtiva do açaí precisa ser compreendida como um sistema complexo, onde cada elo da cadeia e ator, deve ser evidenciado, sendo necessário fomentar ações de gestão e planejamento participativo, fortalecendo os processos associativistas.

Os resultados das pesquisas precisam ser propriadas pelos diferentes atores sociais que 
participam do processo, visto o risco da insustentabilidade desse modelo de desenvolvimento. Os impactos negativos das ações de expansão da área produtiva nos ecossistemas de várzea, a partir de eliminação de espécies essenciais ao equilibrio do sistema, podem ser irreversíveis, e não levará à geração efetiva de aumento de renda dos ribeirinhos.

\section{CONCLUSÃO}

O açaí é a base de sustento das famílias que moram às margens dos rios e está entre os principais produtos do Pará, portanto, as políticas públicas precisam continuar subsidiando a população que contribui efetivamente para o PIB do Estado.

Os ribeirinhos não realizam anotações de campo, desconsideram os custos com a mão de obra familiar, assim como, o valor do açaí enquanto produto alimentício, sem incluí-lo na contabilidade das despesas com alimentação. $\mathrm{O}$ valor correspondente ao lucro real para os ribeirinhos que acaba sendo desconsiderado frente às demais entradas de recursos advindos de outras atividades e de programas sociais.

$\mathrm{O}$ adensamento de plantas por hectare, enquanto orientação para aumento de produtividade gera eliminação de espécies importantes na diversidade da várzea além de esbarrar em fator limitante que é a própria capacidade de suporte da área, que pode estar comprometendo o resultado esperado.

Destaca-se a necessidade de rever as políticas públicas de crédito, fomento e ATER, nos diferentes níveis de governo, municipal, estadual e nacional, de forma a qualificar as atividades nos ecossistemas de várzea, e atenção às áreas de monocultivo. Há potencial para se estabelecer a inserção do ribeirinho na verticalização da cadeia de produção na etapa industrial, proporcionando de fato a inclusão social e melhor distribuição de renda, mas é necessário processo de capacitação em gestão e processos associativistas.

O principal problema de ordem produtiva, é a variação de preço frente a sazonalidade do produto. O ribeirinho pode deixar de ser um mero fornecedor de matéria prima dentro da cadeia produtiva, passando a ser protagonista, participando do processo de beneficiamento do produto, através das agroindústrias em sistema cooperativista.

Há necessidade de planejamento participativo das diversas atividades que afetam o território, de políticas públicas de desenvolvimento, crédito, fomento e ATER, mas também, no que concerne a gestão de suas formas associativistas, com base na realidade local, evidenciando suas potencialidades. As instituições estatais do setor produtivo precisam trabalhar de forma parceira e focada no estabelecimento de indústrias locais, gestadas pelos próprios ribeirinhos.

Os agentes governamentais e demais membros da cadeia produtiva precisariam investir em políticas públicas de incentivo à pesquisa de técnicas e tecnologias locais, na busca pelo aumento de produção e produtividade durante o período da entressafra, o que nesse caso, realizam a quebra da floração induzindo desta forma seu lançamento para o período de entressafra, que precisa ser aprimorado, mas também, com foco em atividades coletivas de cunho social e ambiental.

Desta forma, as políticas públicas para o açaí em áreas de várzea precisam deixar de focar as soluções de crescimento de produção e produtividade baseadas em intervenções de médio e alto impacto, inclusive pela própria limitação espacial, que coloca em xeque os limites desse aumento, além das problemáticas advindas do adensamento da espécie e a homogeneização da paisagem.

Desenvolvimento sustentável é possível, mas precisa ser buscado, a partir dos contextos locais, tratando os diferentes aspectos que atuam no processo, que estão para além do fator econômico. 


\section{REFERÊNCIAS}

ANDRADE, L. C.; PORTELA, R. S.; FERRÃO, E. S.; SOUZA, A. L.; REIS, A. A. Adoção de novos paradigmas na organização e gestão de empreendimentos solidários: um estudo sobre o processo produtivo do açaí através das associações e cooperativas no território rural do Baixo Tocantins - Pará - Brasil. XLVI Congresso da Sociedade Brasileira de Economia, Administração e Sociologia Rural. Anais... Rio Branco - Acre, 20 a 23 de julho de 2008.

BEZERRA, V. S.; FREITAS-SILVA, O.; DAMASCENO, L. F. Açaí: produção de frutos, mercado e consumo. In: JORNADA CIENTÍFICA DA EMBRAPA AMAPÁ, 2., 2016, Macapá. Resumos... Macapá: Embrapa Amapá, 2016.

COMPANHIA NACIONAL DE ABASTECIMENTO - CONAB. Produtos da sociobiodiversidade, safra 2013/2014 - Volume III. Brasília, DF, 2013.

COMPANHIA NACIONAL DE ABASTECIMENTO - CONAB. Produtos da sociobiodiversidade, safra 2015/2016 - Volume II. Brasília, DF, 2015.

COMPANHIA NACIONAL DE ABASTECIMENTO - CONAB. Produtos da sociobiodiversidade, safra 2018/2019 - Brasília, DF, 2019.

COSTA, F de A.; ANDRADE, W. D. C. de; SILVA, F. C. F. da. O arranjo produtivo de frutas na região polarizada por Belém do Pará. In: LASTRES, E. CASSIOLATO, J. (ORG) Estratégias para o desenvolvimento: um enfoque sobre Arranjos Produtivos Locais do Norte, Nordeste e Centro-Oeste Brasileiros. Rio de Janeiro: E-Papers. 2006.

COSTA, R.C.; Nunez, C.V. Cadeias produtivas \& seus ambientes / Reinaldo Corrêa Costa, Cecilia Verônica Nunez (organizadores). -- Manaus: Editora INPA, 2017.

DIEGUES, Antônio Carlos. Os Saberes Tradicionais e a Biodiversidade no Brasil. São Paulo NUPAUB/USP, PROBIO/ MMA, CNPq, 1999.

HOMMA, A. K. O. Extrativismo vegetal ou plantio: qual a opção para a Amazônia? In: HOMMA, A. K. O. (ed.). Extrativismo vegetal na Amazônia: história, ecologia, economia e domesticação. Brasília, DF: Embrapa, 2014.

INSTITUTO BRASILEIRO DE GEOGRAFIA E ESTATÍSTICA - IBGE. Cidades, 2014.

Disponível em: $<$ http://www.cidades.ibge.gov.br/xtras/perfil.php?lang=\&codmun=150010\&search= ||infogr\%E1ficos:-informa\%E7\%F5es-completas> Acesso em 21 mai. 2016.

INSTITUTO BRASILEIRO DE GEOGRAFIA E ESTATÍSTICA - IBGE. Cidades, 2016.

Disponível em: http://www.cidades.ibge.gov.br/xtras/perfil.php?lang=\&codmun=150010\&search $=\| \mathbf{i}$ nfogr\%E1ficos:-informa\%E7\%F5es-completas> Acesso em 19 agosto. 2019.

INSTITUTO BRASILEIRO DE GEOGRAFIA E ESTATÍSTICA - IBGE. Cidades, 2018.

Disponível em: http://www.cidades.ibge.gov.br/xtras/perfil.php?lang=\&codmun=150010\&search=\|i nfogr\%E1ficos:-informa\%E7\%F5es-completas> Acesso em 22 agosto. 2019.

INSTITUTO NACIONAL DE COLONIZAÇÃO AGRÍCOLA - INCRA, mapa assentamentos rurais. 2016. Disponível em: <http://acervofundiario.incra.gov.br/i3geo/interface/incra.html?i2dr3h6 pqv4ans097od4sbvus6> Acesso em 15 ago. 2016. 
JARDIM, M. A. G. Aspectos da produção extrativista do açaizeiro (Euterpe oleracea Mart.) no estuário Amazônico. Série Botânica, 12(1). Museu Paraense Emílio Goeldi, Belém, PA, 1996.

KLIEMANN, F. J.; SOUZA, S. O. Desenho, Análise e Avaliação de Cadeias Produtivas. Porto Alegre; Bookmamn, 2003.

LOPES, M. L. B.; SANTANA A.C. O mercado do fruto do açaizeiro (Euterpe oleracea Mart.) no estado do Pará. In: Carvalho DF (Org.) Economia da Amazônia nos anos 90. Belém, Universidade da Amazônia. p.65-84.2005.

MOURÃO, L. Do açai ao palmito: usos de produtos e subprodutos do açaizeiro no estuário amazônico. In: Seminário açaí (Euterpe oleracea), 1996, Belém. Resumos. Belém: NAEA/MPEG/ Embrapa/SECTAM, 1996.

MOURÃO, L. História e natureza: do açaí ao palmito. Revista Territórios e Fronteiras. V.3 N.2.Universidade Federal do Mato Grosso, Mato Grosso, MT, 2010.

NEVES, M. M.; PENA, H. W. A.; BAHIA, P. Q.: "Planejamento da produção e a gestão financeira do cultivo do açaí no estado do Pará, Amazônia, Brasil”, In Observatorio de la Economía Latinoamericana, Número 198, 2014. Texto completo In http://www.eumed.net/cursecon/ecolat/ br/14/cultivo-azai.hmtl

NOGUEIRA, O. L.; FIGUEIREDO, F.J.C.; MULLER, A. A. Açaí: manejo de cultivo. Sistemas de produção. Embrapa Amazônia Oriental, 2005. Belém, Pará.

NOGUEIRA, O. L.; HOMMA, A. K. O. Importância do manejo de recursos extrativos em aumentar a capacidade de suporte: o caso de açaizeiros (Euterpe oleracea Mart,) no estuário amazônico In HOMMA, A. K. O. (ed.). Extrativismo Vegetal na Amazônia: história, ecologia, economia e domesticação. Brasília, DF: Embrapa, 2014.

OLIVEIRA, L. P. de. Programa de Desenvolvimento da Cadeia Produtiva do Açaí no Estado do Pará - PROAÇAÍ. Belém, Pará, SEDAP, 2016.

OLIVEIRA, M. S. P.; FARIAS NETO, J. T.; PENA, R. dá S. Açaí: técnicas de cultivo. Fortaleza: Instituto Frutal, 2007.

ROGEZ, Hervé. Açaí: Preparo, Composição e Melhoramento da Composição. Belém: EDFPA, 2000.

SANTANA, A.C.; CARVALHO, D.F.; MENDES, F.A.T. Organização e competitividade das empresas de polpas de frutas no Estado do Pará: 1995 a 2004. Belém, Unama, 2006.

SCHIRMANN, Gabriela da Silva. Composição em ácidos graxos do açaí (euterpe edulis) de diversas regiões de Santa Catarina 2009. 91 f. Dissertação (Mestrado em Agroecossistemas) Centro de Ciências Agrárias, Universidade Federal de Santa Catarina, Florianópolis, SC, 2009.

TAVARES, G. S.; HOMMA, A. K. O.” Comercialização do açaí no Estado do Pará: alguns comentários", Revista Observatório de La Economía Latino-americana, Brasil (septiembre 2015). Em línea: http://www.eumed.net/cursecon/ecolat/br/15/acai-para.html

YIN, R. K. Enhancing the quality of case studies in health services research. Health Service Research, v.34, n.5, p.1209-1224, dec. 1999. 